\title{
The effect of tracheal tube size on air leak around the cuffs
}

\author{
Jin-Young Hwang ${ }^{1}$, Sang-Hyun Park ${ }^{1}$, Sung-Hee Han ${ }^{1}$, Seong-Joo Park ${ }^{1}$, Soo-kyung Park ${ }^{2}$, and \\ Jin-Hee Kim ${ }^{1}$
}

Department of Anesthesiology and Pain Medicine, ${ }^{1}$ Seoul National University Bundang Hospital, Seongnam, ${ }^{2}$ Seoul National University Hospital, Seoul, Korea

Background: This randomized single-blinded, cross-over study was done to evaluate the influence of the size of tracheal tubes on air leaks around the cuffs.

Methods: In a benchtop model, the number of longitudinal folds on the cuffs was evaluated for different sizes of tracheal tubes. In an anesthetized patient study, thirty patients scheduled for elective surgery under general anesthesia were included. After induction of anesthesia, the trachea was intubated with two sizes of tracheal tubes in a random sequence: in men, internal diameter of $7.5 \mathrm{~mm}$ and $8.0 \mathrm{~mm}$; in women, internal diameter of $7.0 \mathrm{~mm}$ and 7.5 $\mathrm{mm}$. After tracheal intubation with each tube, air leak pressures were evaluated at intracuff pressures of 20, 25 and 30 $\mathrm{cmH}_{2} \mathrm{O}$ by auscultation. To calculate the tracheal tube resistance (R), an inspiratory pause of $20 \%$ was applied and the resulting peak airway pressure $\left(\mathrm{P}_{\text {peak }}\right)$, plateau pressure $\left(\mathrm{P}_{\mathrm{pl}}\right)$ and mean expiratory tidal volume (Flow) were inserted in the formula $\mathrm{R}=\left(\mathrm{P}_{\text {peak }}-\mathrm{P}_{\mathrm{pl}}\right) /$ Flow.

Results: More longitudinal folds of the tracheal tube cuffs occurred in larger sized tubes compared to the smaller ones in a benchtop model. Air leakage was significantly less for the smaller tracheal tubes than for the larger ones for each gender at intracuff pressures of 20, 25 and $30 \mathrm{cmH}_{2} \mathrm{O}$. Tracheal tube resistances were not significantly altered by the size of tracheal tube.

Conclusions: The use of a smaller tracheal tube within an acceptable size can reduce air leakage around the cuff without significantly changing the tracheal tube resistance. (Korean J Anesthesiol 2011; 61:24-29)

Key Words: Anesthesia, Intratracheal, Intubation.

Received: October 4, 2010. Revised: 1st, November 12, 2010; 2nd, December 16, 2010; 3rd, January 3, 2011. Accepted: January 3, 2011. Corresponding author: Jin-Hee Kim, M.D., Department of Anesthesiology, Seoul National University Bundang Hospital, 166, Gumi-ro, Bundang-gu, Seongnam 463-707, Korea. Tel: 82-31-787-7505, Fax: 82-31-787-4063, E-mail: anesing1@snu.ac.kr

(c) This is an open-access article distributed under the terms of the Creative Commons Attribution Non-Commercial License (http:// creativecommons.org/licenses/by-nc/3.0/), which permits unrestricted non-commercial use, distribution, and reproduction in any medium, provided the original work is properly cited. 


\section{Introduction}

Cuffed tracheal tubes are routinely used for airway management. It is important to maintain an adequate cuff pressure since it is well known that a high cuff pressure can cause tracheal ischemic complications while a low cuff pressure may lead to aspiration or gas leakage [1]. The use of high-volume and low-pressure (HVLP) tracheal cuffs has reduced cuff-induced tracheal damage because these cuffs conform passively to tracheal contours as they expand during inflation and the cuff inflation pressure is assumed to be equal to the cuff-totrachea pressure [2]. Taking into consideration adequate size of a tracheal tube with HVLP cuffs, the cuff diameter is larger than the tracheal diameter, and the tracheal tube resistance is clinically tolerable. However, longitudinal folds of a HVLP cuff occur upon inflation within the trachea, because the cuff diameter is greater than the tracheal diameter, and these folds provide channels for aspiration or gas leakage [3-5]. The relation between the diameter of the trachea and the tracheal cuff size (or tracheal tube size) [3] and the material or shape of the cuffs $[4,6]$ has an influence on those folds, which might alter air leakage around the cuff.

However, no study has been undertaken to determine whether tracheal cuff size or tracheal tube size affect air leakage around the cuffs. The hypothesis of this study is that the use of a smaller sized tracheal tube would reduce air leakage around the cuff. Therefore, we did an in vitro study and a randomized single-blinded, cross-over study to assess the influence of the size of tracheal tubes on air leakage.

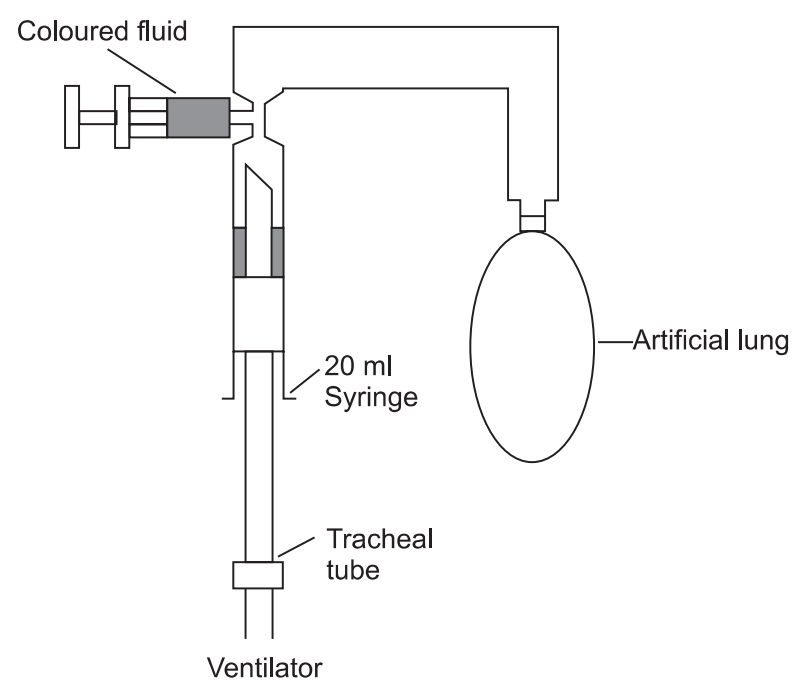

Fig. 1. Air leakage model.

\section{Materials and Methods}

\section{Benchtop Model}

In an in vitro setup, we investigated the number of longitudinal folds of tracheal tube cuffs during inflation within a cylinder. The air leakage model is shown in Fig. 1. A rigid cylinder (20 ml syringe barrel, Safti Syrynge ${ }^{\circledR}$, Becton Dickinson, Korea), $2 \mathrm{~cm}$ in diameter was intubated with different sized tracheal tubes (Safey-Flex ${ }^{\mathrm{TM}}$, Mallinckrodt, Athlone, Ireland; internal diameter $7.0 \mathrm{~mm}, 7.5 \mathrm{~mm}$ and $8.0 \mathrm{~mm}$ ) using a random sequence.

The characteristics of the tracheal tube cuffs are presented in Table 1. The cylinder was suspended upside down and the tube cuffs were inflated to $25 \mathrm{cmH}_{2} \mathrm{O}$ with a handheld aeroid manometer (VBM Medizintechnik GmbH, Germany). An artificial lung made of latex was linked to the distal part of the cylinder, and the tube was connected to a ventilator (Aestiva 7900 SmartVent, Datex-Ohmeda Inc.). With $3.5 \mathrm{ml}$ of blue-dyed water placed above the cuff, the expiratory valve was closed and the artificial lung was expanded with a constant flow of oxygen at $5 \mathrm{~L} / \mathrm{min}$. When a fluid leak around the cuffs occurred, an observer blinded to the size of the tracheal tube counted the longitudinal folds of the cuffs and photographed their appearance. The experiment was repeated five times with new tubes for each size.

\section{Air leakage with anesthetized patients}

This study was approved by the Institutional Review Board of our hospital. Written informed consent was obtained during the preoperative visit. Fifteen male and fifteen female ASA I-II patients between 20 and 70 years of age scheduled for elective surgery under general anesthesia at our hospital were included. Patients were excluded if they had an upper airway or vocal cord disease, a history of tracheostomy, tracheal stenosis, a predicted difficult airway, or a risk of barotrauma.

After premedication with $0.03 \mathrm{mg} / \mathrm{kg}$ of intravenous midazolam, patients were transported to the operating theatre. Intraoperative monitoring included noninvasive arterial pressure, electrocardiography (ECG), pulse oximetry, and end-tidal $\mathrm{CO}_{2}$. Anesthetic management was standardized

Table 1. Characteristics of the Tracheal Tube Cuffs

\begin{tabular}{lccc}
\multicolumn{1}{c}{ ID $(\mathrm{mm})$} & 7.0 & 7.5 & 8.0 \\
\hline Length (cm) & 4.0 & 4.0 & 4.4 \\
Diameter (mm) & 24 & 26 & 28 \\
Shape & & Spindle shape & \\
Material & & Polyvinylchloride (PVC) \\
\hline
\end{tabular}


according to the following protocol. After preoxygenation for 3 minutes, anesthesia was induced with $1 \mu \mathrm{g} / \mathrm{kg}$ of intravenous remifentanil and $1.5-2 \mathrm{mg} / \mathrm{kg}$ of propofol. After achieving maximal neuromuscular blockade with $0.6 \mathrm{mg} / \mathrm{kg}$ of intravenous rocuronium, tracheal intubation was successfully performed with one of two tracheal tubes (determined by block randomization): in male patients, an internal diameter of $7.5 \mathrm{~mm}$ and $8.0 \mathrm{~mm}$ was used; in female patients, an internal diameter of $7.0 \mathrm{~mm}$ and $7.5 \mathrm{~mm}$ was used in a random sequence. By direct laryngoscopy, the tracheal tube was introduced until the proximal circumferential black line on the tube passed through the level of the vocal cords, and the tracheal tube was secured at the upper lip. The cuff was then inflated and the pilot balloon of the tracheal tube was connected to a handheld aeroid manometer (VBM Medizintechnik $\mathrm{GmbH}$, Sulz, Germany). Anesthesia was maintained with a 2 vol\% of sevoflurane with $100 \%$ oxygen at $5 \mathrm{~L} / \mathrm{min}$.

Air leak pressure was measured by closing the expiratory valve of the circular anesthetic breathing system and increasing the inspiratory pressure with a constant flow of $5 \mathrm{~L} / \mathrm{min}$. The pressure at which an audible air leak occurred was noted [7]. Air leak pressures at intracuff pressure 20, 25 and $30 \mathrm{cmH}_{2} \mathrm{O}$ were evaluated respectively by auscultation with a stethoscope just lateral to the thyroid cartilage by an anesthesiologist unaware of the intracuff pressure. To prevent lung barotrauma, the expiratory valve was opened as soon as the peak airway pressure reached $40 \mathrm{cmH}_{2} \mathrm{O}$. Air leak pressure was measured three times at each intracuff pressure, and was recorded as the mean leak pressure. If no air leak occurred at the peak airway pressure of $40 \mathrm{cmH}_{2} \mathrm{O}$, the air leak pressure was recorded as $40 \mathrm{cmH}_{2} \mathrm{O}$.
After measuring the air leak pressure, an intracuff pressure of $30 \mathrm{cmH}_{2} \mathrm{O}$ was maintained and the tracheal tube was connected to a ventilator. Volume-controlled mechanical ventilation was performed at a respiratory frequency of 10 breaths/min with a tidal volume (TV) of $10 \mathrm{ml} / \mathrm{kg}$ based on predicted body weight (PBW), and an inspiratory: expiratory (I : E) ratio of $1: 2$. PBW was calculated using the following formula: in men, PBW $(\mathrm{kg})$ $=50+0.91$ [height $(\mathrm{cm})-152.4$ ]; in women, PBW $(\mathrm{kg})=45.5$ +0.91 [height $(\mathrm{cm})-152.4$ ] [8]. To calculate the tracheal tube resistance $(\mathrm{R})$, an inspiratory pause of $20 \%$ was applied and the resulting peak airway pressure $\left(\mathrm{P}_{\text {peak }}\right)$, plateau pressure $\left(\mathrm{P}_{\mathrm{pl}}\right)$ and mean expiratory tidal volume measured three times were inserted into the formula $\mathrm{R}=\left(\mathrm{P}_{\text {peak }}-\mathrm{P}_{\mathrm{pl}}\right) /$ Flow [9]. After measuring the air resistance, the tracheal tube was removed, and the trachea was intubated with another sized tube. Air leak pressure and air resistance were measured again as described above.

The primary outcome of this study was the air leak pressure around the cuffs. Sample size calculation was done using a power analysis computer program $\mathrm{G}^{*}$ Power 3.1 [10]. In 30 male patients, a pilot study was done with different sized tracheal tubes (ID $7.5 \mathrm{~mm}$ and ID $8.0 \mathrm{~mm}$ ) at an intracuff pressure of 25 $\mathrm{cmH}_{2} \mathrm{O}$. From this pilot study, the mean and standard deviation of the leak pressure differences were 5 and 6 , respectively. From these results, the total sample size required was 14 patients with an alpha of 0.05 and a power of 0.9 (one-tailed test). Therefore, 15 patients in each gender were enrolled to compensate for possible dropouts. Values are expressed as mean (range) or mean \pm SD. Paired t-test was used to analyze the change in the air leakage pressure and air resistance with respect to the size
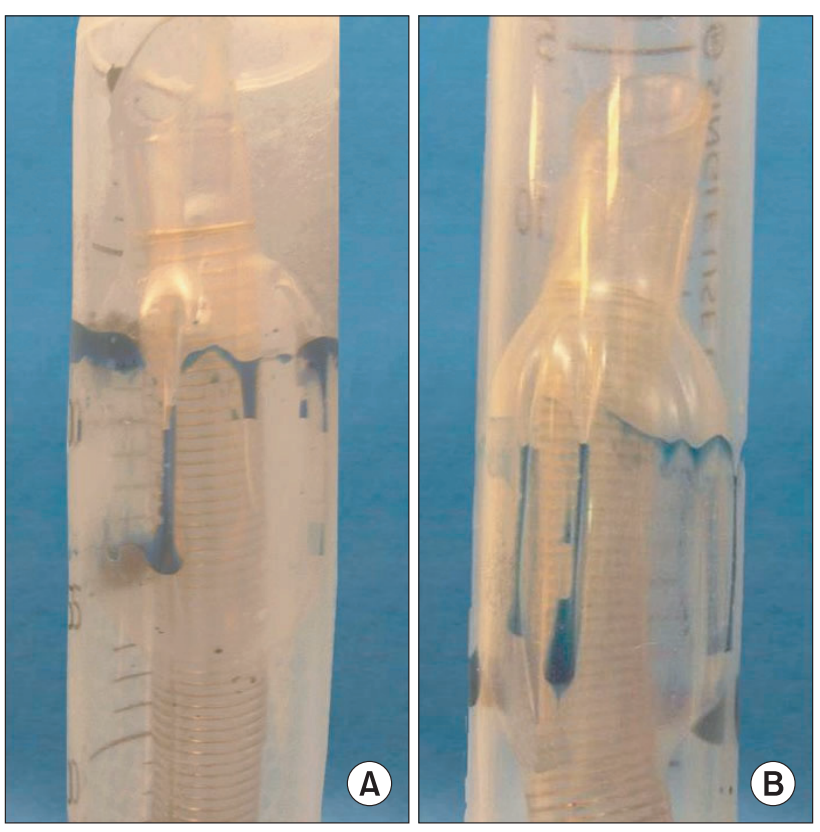

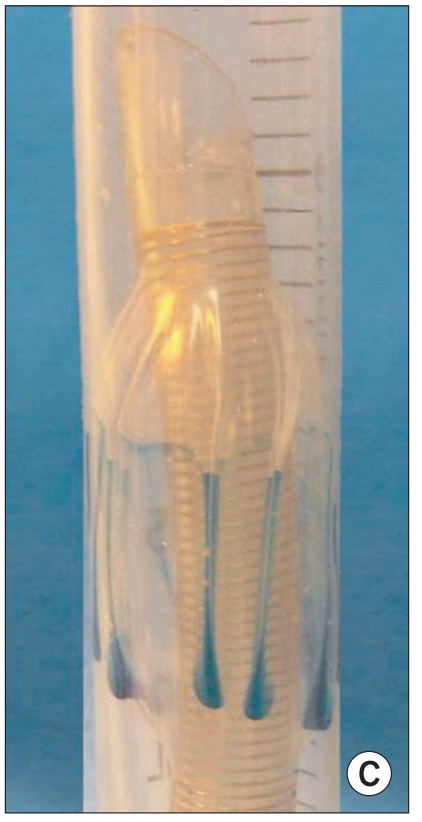

Fig. 2. (A) Longitudinal folds in a tracheal tube cuff (ID $7.0 \mathrm{~mm}$ ) and (B) Longitudinal folds in a tracheal tube cuff (ID $7.5 \mathrm{~mm}$ ) (C) Longitudinal folds in a tracheal tube cuff (ID $8.0 \mathrm{~mm}$ ) Smaller size tubes show less longitudinal folds around the cuff than the larger ones. 
of tracheal tube. Fisher's exact test was used to analyze the incidence of air leakage pressure below $20 \mathrm{cmH}_{2} \mathrm{O}$ or above 40 $\mathrm{cmH}_{2} \mathrm{O}$. Statistically significance was accepted for $\mathrm{P}$ value of $<$ 0.05 .

\section{Results}

\section{Benchtop study}

More longitudinal folds of tracheal tube cuffs occurred in the larger size tubes compared to the smaller ones; internal diameter $7.0 \mathrm{~mm}$ vs. $7.5 \mathrm{~mm}$ vs. $8.0 \mathrm{~mm}, 4.1 \pm 1.1$ vs. $6.8 \pm 0.8$ vs. $9.5 \pm 1.3$, respectively, $\mathrm{P}=0.024$ (Fig. 2).

\section{Anesthetized patient study}

One female patient refused to participate: therefore, fifteen male and fourteen female patients were included. The patients' characteristics and tracheal tube resistances are summarized in Table 2. The resistances of the tracheal tubes were not

Table 2. Patients' Characteristics and Tracheal Tube Resistance

\begin{tabular}{lcc}
\hline & $\begin{array}{c}\text { Male patients } \\
(\mathrm{n}=15)\end{array}$ & $\begin{array}{c}\text { Female patients } \\
(\mathrm{n}=14)\end{array}$ \\
\hline Age & $45.8(21-69)$ & $49.9(28-65)$ \\
Height $(\mathrm{cm})$ & $173.4 \pm 5.6$ & $158 \pm 4.5$ \\
Weight $(\mathrm{kg})$ & $78.7 \pm 11.3$ & $57.2 \pm 11.5$ \\
Tracheal tube resistance & & \\
$\left(\mathrm{cmH} \mathrm{H}_{2} \mathrm{O} \cdot \mathrm{sec} / \mathrm{ml}\right)$ & & $9.25 \pm 2.19$ \\
ID 7.0 $(\mathrm{mm})$ & & $9.08 \pm 2.24$ \\
ID 7.5 $(\mathrm{mm})$ & $10.01 \pm 4.06$ & \\
ID $8.0(\mathrm{~mm})$ & $9.71 \pm 3.91$ & \\
\hline
\end{tabular}

Values are the means (range) for age or means \pm SD.

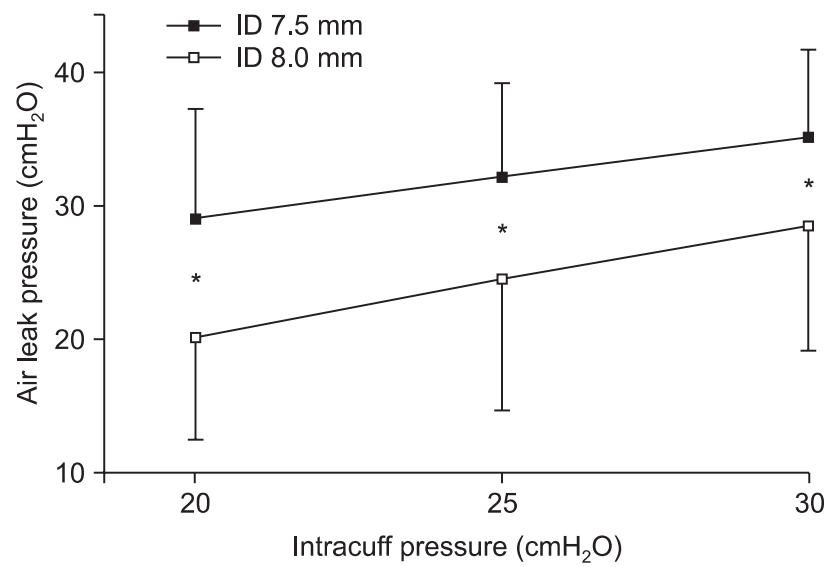

Fig. 3. Air leak pressure in male patients. Values represent the means \pm SD. The error bars indicate $1 \mathrm{SD} .{ }^{*} \mathrm{P}<0.05$ compared to different sized tubes significantly affected by the internal diameters of the tracheal tubes.

In the male patients, the leak pressure for the smaller-sized tracheal tube (ID $7.5 \mathrm{~mm}$ ) was significantly higher than that in the larger one (ID $8.0 \mathrm{~mm}$ ) at all intracuff pressures (20, 25 and $30 \mathrm{cmH}_{2} \mathrm{O}$ ) (Fig. 3). In the female patients, the leak pressure was also significantly higher for the smaller-sized tracheal tube (ID $7.0 \mathrm{~mm}$ ) than for the larger one (ID $7.5 \mathrm{~mm}$ ) at all intracuff pressures (20, 25 and $\left.30 \mathrm{cmH}_{2} \mathrm{O}\right)$ (Fig. 4).

No patient experienced significant postoperative complications associated with intubation including laryngeal edema.

\section{Discussion}

The main result of the present study is that the smaller tracheal tube within an acceptable size had a significantly higher leak pressure than the larger tracheal tube at the same intracuff pressure without any significant change of airway resistance.

High-volume and low-pressure (HVLP) cuffs of tracheal tube were designed to prevent tracheal ischemic damage $[2,11,12]$. However, it is clear that HVLP tracheal tube cuffs do not effectively prevent leakage of fluid into the lower airway, since longitudinal folds inevitably occur in a cuff inflated within a trachea, because the cuff diameter is not greater than the tracheal diameter $[13,14]$. A previous in vitro study demonstrated that fluid leaks around the cuffs were minimized at lower tracheal cuff to tracheal diameter ratios [3]. However, there has been no study about the relationship between air leaks and the size of the tracheal tube.

We assessed the influence of the size of the tracheal tube on air leakage around the cuff. A smaller sized tracheal tube of was found to have a significantly higher air leak pressure than a

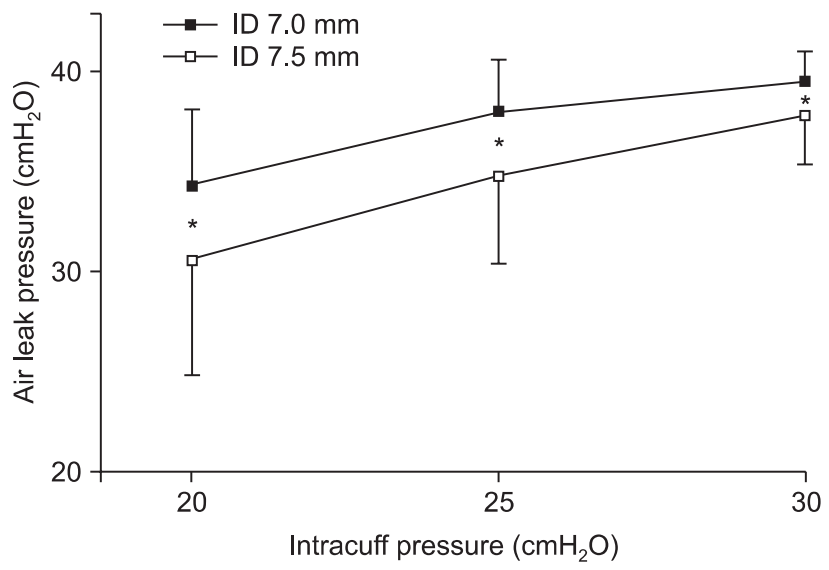

Fig. 4. Air leak pressure in female patients. Values represent the means \pm SD. The error bars indicate $1 \mathrm{SD}$. ${ }^{*} \mathrm{P}<0.05$ compared to different sized tubes. 
larger tracheal tube at clinically compatible intracuff pressures $\left(20,25\right.$, and $\left.30 \mathrm{cmH}_{2} \mathrm{O}\right)$. There is no clear explanation about these results. In the present study, we observed the number of longitudinal folds on the cuffs inflated within a cylinder in a benchtop model, and found that more longitudinal folds developed as the tube size became larger. Therefore, when the cuffs are inflated within the trachea, fewer invaginations develop in smaller cuffs, and that might reduce air leak. This explanation is in line with the result of the previous study [3].

The effect of tracheal tube resistance on the work of breathing has caused much concern about weaning off a patient from mechanical ventilatory support. Numerous studies have shown that tracheal tube resistance significantly impedes spontaneous breathing [15-17], whereas others suggested that tracheal tube resistance may not be important when the appropriate sized tube is chosen and the patients' pulmonary function has improved to the point where weaning off can be considered $[18,19]$. Tracheal tubes cause airflow resistance, which depends on several parameters. The resistance increases as the viscosity of the gas mixture is increased, the inner diameter is decreased, and the length is increased [9]. Generally, tracheal tubes with larger internal diameter are also longer. Considering the use of tracheal tubes in clinical practice, we calculated the tracheal tube resistance without any modification of the tube length, and there was no significant difference in tracheal tube resistance in accordance with the change of tube size.

Some limitations of the present study should be noted. First, we did air leakage testing by auscultation with a stethoscope just lateral to the thyroid cartilage. This method might result in a variation of repeated measurement, because accurate determinations of small leak volumes required careful control of the inspiratory flow rate in order to avoid errors created by equipment hysteresis. Therefore, the gas flow rates and compositions were fixed and the inspiratory pressure was increased by constant flow, and we measured the air leak pressure three times at each intracuff pressure, and calculated the mean air leak pressure. Second, in the present study, if no air leak was detected at a peak airway pressure of $40 \mathrm{cmH}_{2} \mathrm{O}$, the air leak test was stopped to prevent barotrauma and the air leak pressure was recorded as $40 \mathrm{cmH}_{2} \mathrm{O}$. If the study was done excluding these patients, the data might show more limited results. In the present study, the incidence of air leak pressure above $40 \mathrm{cmH}_{2} \mathrm{O}$ was higher in male patients with a tracheal tube ID of $7.5 \mathrm{~mm}$ and higher in female patients with a tracheal tube ID of $7.0 \mathrm{~mm}$. Therefore, if the actual air leak pressure were estimated, the significance of the difference would increase. Third, we evaluated air leak pressure immediately after tracheal intubation; therefore, the change in air leak pressure over time is not clear. Fourth, this study was focused on air leakage in accordance with the tube size. Although pulmonary aspiration is more serious problem with an inadequate seal, air leakage would be also problematic in clinical settings. Further evaluation about pulmonary aspiration with different sized tube is required.

In conclusion, the present study shows that smaller tracheal tubes in a clinically acceptable range significantly reduced air leakage around the cuffs compared to larger ones without any significant change in the airflow resistance. In patients with reduced pulmonary compliance and high ventilatory pressures, smaller but acceptable-sized tracheal tubes enable some reduction in tracheal ischemic damage and air leakage.

\section{References}

1. Zanella A, Cressoni M, Epp M, Stylianou M, Kolobow T. A doublelayer tracheal tube cuff designed to prevent leakage: a bench-top study. Intensive Care Med 2008; 34: 1145-9.

2. Guyton DC, Barlow MR, Besselievre TR. Influence of airway pressure on minimum occlusive endotracheal tube cuff pressure. Crit Care Med 1997; 25: 91-4.

3. Pavlin EG, VanNimwegan D, Hornbein TF. Failure of a highcompliance low-pressure cuff to prevent aspiration. Anesthesiology 1975; 42: 216-9.

4. Young PJ, Blunt MC. Improving the shape and compliance characteristics of a high-volume, low-pressure cuff improves tracheal seal. Br J Anaesth 1999; 83: 887-9.

5. Young PJ, Rollinson M, Downward G, Henderson S. Leakage of fluid past the tracheal tube cuff in a benchtop model. Br J Anaesth 1997; 78: 557-62.

6. Dullenkopf A, Schmitz A, Frei M, Gerber AC, Weiss M. Air leakage around endotracheal tube cuffs. Eur J Anaesthesiol 2004; 21: 448-53.

7. Aker J. An emerging clinical paradigm: the cuffed pediatric endotracheal tube. AANA J 2008; 76: 293-300.

8. Ventilation with lower tidal volumes as compared with traditional tidal volumes for acute lung injury and the acute respiratory distress syndrome. The Acute Respiratory Distress Syndrome Network. N Engl J Med 2000; 342: 1301-8.

9. El-Khatib MF, Husari A, Jamaleddine GW, Ayoub CM, Bou-Khalil P. Changes in resistances of endotracheal tubes with reductions in the cross-sectional area. Eur J Anaesthesiol 2008; 25: 275-9.

10. Faul F, Erdfelder E, Lang AG, Buchner A. G*Power 3: a flexible statistical power analysis program for the social, behavioral, and biomedical sciences. Behav Res Methods 2007; 39: 175-91.

11. Seegobin RD, van Hasselt GL. Endotracheal cuff pressure and tracheal mucosal blood flow: endoscopic study of effects of four large volume cuffs. Br Med J (Clin Res Ed) 1984; 288: 965-8.

12. Bernhard WN, Cottrell JE, Sivakumaran C, Patel K, Yost L, Turndorf H. Adjustment of intracuff pressure to prevent aspiration. Anesthesiology 1979; 50: 363-6.

13. Young PJ, Basson C, Hamilton D, Ridley SA. Prevention of tracheal aspiration using the pressure limited tracheal tube cuff. Anaesthesia 1999; 54: 559-63.

14. Lucangelo U, Zin WA, Antonaglia V, Petrucci L, Viviani M, Buscema G, et al. Effect of positive expiratory pressure and type of tracheal cuff on the incidence of aspiration in mechanically ventilated 
patients in an intensive care unit. Crit Care Med 2008; 36: 409-13.

15. Shapiro M, Wilson RK, Casar G, Bloom K, Teague RB. Work of breathing through different sized endotracheal tubes. Crit Care Med 1986; 14: 1028-31.

16. Bersten AD, Rutten AJ, Vedig AE, Skowronski GA. Additional work of breathing imposed by endotracheal tubes, breathing circuits, and intensive care ventilators. Crit Care Med 1989; 17: 671-7.
17. Iturralde R, Hogman B, Engstrom G. Ventilator-imposed work of breathing. Chest 1986; 90: 785-7.

18. Weissman C. Flow-volume relationships during spontaneous breathing through endotracheal tubes. Crit Care Med 1992; 20: 61520.

19. Branson RD. Endotracheal tubes and imposed work of breathing: what should we do about it, if anything? Crit Care 2003; 7: 347-8. 